\title{
Descobertas arqueológicas demonstram a existência de pessoas, lugares e eventos descritos em solo bíblico
}

\section{Archaeological discoveries demonstrate the existence of people, places and events described in bible soil}

DOI: $10.46814 / \operatorname{lajdv3n4-046}$

Recebimento dos originais: 01/05/2021

Aceitação para publicação: 31/06/2021

\section{Anderson Martelli}

Mestre Ciências Biomédicas pelo Centro Universitário da Fundação Hermínio Ometto - FHO; Biólogo e Diretor da Secretaria de Meio Ambiente de Itapira-SP; Professor na Faculdade UNIMOGI, Mogi Guaçu-SP

Avenida Rodrigo Mazzon, 601, Parque Real Guaçu Mogi Guaçu / SP

E-mail: martellibio@ hotmail.com

\section{Fabiana Palermo Martelli}

Pós-Graduação em Gestão Financeira, Controladoria e Auditoria IB POLI, Jaguariúna-SP. Graduação em Ciências da Computação, Unipinhal, Espírito Santo do Pinhal-SP.

Rua Ary Crosgnac, 470, Jd Cristina, Mogi Guaçu / SP

E-mail: martelli.bio@gmail.com

\section{RESUMO}

Os livros que compõe a Bíblia Sagrada são documentos que começaram a ser escrito durante 1.300 anos, entre o ano 1.250 a.C. e o ano 100 d.C. dividido em Antigo Testamento, antes de Cristo e Novo Testamento, depois de Cristo. Antes da sua escrita, o povo daquela época vivenciou esses momentos, sendo relatadas e passadas de gerações a gerações. Analisar o contexto cultural e histórico torna-se de extrema valia para os estudos teológicos e científicos conhecendo as descobertas ligadas às passagens bíblicas. Assim, o objetivo desse artigo foi descrever estudos e descobertas arqueológicas evidenciando a existência de pessoas, lugares e eventos descritos em solo bíblico. A pesquisa foi realizada a partir relatos e acontecimentos descritos nesse livro muitas vezes, desacreditados pela ciência e evidenciados atualmente por descobertas arqueológicas publicadas entre os anos de 2007 até o mais atual 2020. Atualmente a arqueologia, geologia, ciências físicas, matemáticas, biológicas e demais ramos da ciência comprovaram muitos acontecimentos descritos na Bíblia. O cristianismo verdadeiro alicerçados nessas escrituras tem favorecido a prosperidade da ciência, a qual vem endossando esses relatos escritos a milhares de anos atrás.

Palavras chave: Bíblia Sagrada, Arqueologia, Ciência, Humanidade, Confiabilidade.

\section{ABSTRACT}

The books that make up the Holy Bible are documents that began to be written during 1,300 years, between the year $1250 \mathrm{BC}$ and the year $100 \mathrm{AD}$, divided into Old Testament, before Christ and New Testament, after Christ. Before its writing, the people of that time experienced these moments, being reported and passed down from generations to generations. Analyzing the cultural and historical context becomes extremely valuable for theological and scientific studies, knowing the discoveries linked to biblical passages. Thus, the aim of this article was to describe archaeological studies and discoveries evidencing the veracity and reliability of the Holy Scriptures. The research was carried out 
from reports and events described in this book many times, discredited by science and currently evidenced by archaeological discoveries published between the years of 2007 until the most current 2020. Currently archeology, geology, physical sciences, mathematics, biological and other branches of science have proven many events described in the Bible. True Christianity grounded in these scriptures has favored the prosperity of science, which has been endorsing these written accounts thousands of years ago.

Keywords: Holy Bible, Archeology, Science, Humanity, Reliability.

\section{INTRODUÇÃO}

É preciso ter em mente que os textos bíblicos foram escritos bem depois dos fatos narrados terem acontecido, e que eles sempre trazem em suas narrativas o contexto, a realidade e as preocupações do período histórico em que foram escritos (KAEFER, 2015). Neste sentido, a arqueologia, é uma forma científica de "ressuscitar" a História e dessa forma, sua relevância em explorar a história bíblica.

Mundialmente a Bíblia Sagrada é exclusivamente a história sagrada, testemunho de crença para os cristãos de todo o mundo, sendo um importante documento doutrinário de acontecimentos reais (MARTELLI, 2019). A fé cristã, cujo livro sagrado é a Bíblia, e a ciência incluindo seus diversos ramos convivem no Ocidente há 20 Séculos. A fé quer dar uma resposta abrangente para o sentido da vida e do mundo a partir da Revelação Divina e a ciência, conhecer toda a realidade segundo a razão que analisa e demonstra. (MAZZAROLO et al., 2015).

A ciência nos capacita a cumprir o mandato de Gênesis 1:28: "E Deus os abençoou [Adão e Eva] e lhes disse: 'Sede fecundos, multiplicai-vos, enchei a Terra e sujeitai-a; dominai sobe os peixes do mar, sobre as aves dos céus e sobre todo animal que rasteja pela Terra” (BÍBLIA SAGRADA, 2011). A ciência nos dá direções para fazer coisas ou "operar" nesse mundo ajudando a viver no universo de Deus e a subjugá-lo (CRAMPTON, 2018). Segundo Marcum (2007), de modo geral, o objetivo das ciências é conhecer o mundo natural explicando seus fenômenos naturais por meio das causas naturais que os antecedem. Segundo muitos cientistas e filósofos da ciência, o objetivo específico da ciência é a verdade, a qual pode ser expressa numa teoria científica ou numa lei natural, isto é, uma concepção da natureza que representa ou corresponde acuradamente a um mecanismo causal que está na base de determinado fenômeno.

A ciência é um dom de Deus, e o livro da Sabedoria é um verdadeiro hino ao saber científico (MAZZAROLO et al., 2015). Isso pode ser evidenciado no livro de Isaias 44:24-25 "Assim diz o Senhor, o seu redentor, que o formou no ventre: "Eu sou o Senhor, que fiz todas as coisas, que sozinho estendi os céus, que espalhei a terra por mim mesmo, que atrapalha os sinais dos falsos profetas e faz 
de tolos os adivinhadores, que derruba o conhecimento dos sábios e o transforma em loucura" (BÍBLIA SAGRADA, 2011).

Após inúmeras pesquisas realizadas por arqueólogos e diversos profissionais das mais variadas áreas da ciência moderna favoreceram novas descobertas que modificaram a maneira de considerar a Bíblia Sagrada (RICAS, 2013). Assim, este estudo procurou retratar novas descobertas arqueológicas e científicas respaldando a fé com evidências e provas materiais enquanto que esta, por sua vez, pode proporcionar à ciência indícios que podem leva-la ao descobrimento de novas e reveladoras verdades do universo físico (RICAS, 2013).

Demonstrar que, apesar de não ter fins científicos, as Escrituras Sagradas são precisas, tanto em suas citações históricas quanto em seus registros dos fenômenos naturais, na Terra e fora dela e desde o meio ambiente até às criaturas vivas (RICAS, 2013). Uma espantosa evidência da inspiração divina da Bíblia é o fato de que muitos princípios da ciência moderna foram registrados na Bíblia muito antes que qualquer cientista os confirmasse experimentalmente (MARTELLI; MARTELLI, 2020). Todas essas questões nos induzem a raciocinar que o ilustre cientista Galileu Galilei e a escritora cristã norte americana Ellen Gould White estavam certos ao relatarem que as Escrituras Sagradas e a natureza são livros escritos pelo mesmo Autor, por isso, não se contradizem, mas se complementam indo de encontro às descrições no livro de Salmos "Regozijem-se os céus e exulte a terra! Ressoe o mar e tudo o que nele existe! Regozijem-se os campos e tudo o que neles há! Cantem de alegria todas as árvores da floresta” Salmos 96:11-12 (BÍBLIA SAGRADA, 2011).

As teorias científicas propostas estão sempre modificando de acordo com o avanço e as descobertas da ciência, mas a Bíblia continua intacta e sustentável desde o seu registro inspirado (LAPA, 2009). Neste sentido, as evidências arqueológicas descobertas em relação aos textos bíblicos podem corroborar com a existência de pessoas, lugares e até eventos específicos mencionados neste livro sagrado. Suas contribuições podem não ser essenciais para o crente, embora sejam edificantes para uma fé já estabelecida (RANDALL, 2015).

Enquanto alguns cientistas declaram que não acreditam em Deus, outros acreditam e utilizam sua inteligência para provar a veracidade das Escrituras Sagradas e a palavra divina de Deus (MARTELLI; MARTELLI, 2020). Assim, a arqueologia pode ajudar o incrédulo que é desafiado pelas alegações de que os eventos e os personagens da Bíblia são totalmente fictícios. Certamente, os dados arqueológicos não podem, por si mesmos, resultar em conversão, pois somente o Espírito Santo tem poder para fazer isso, mas, por meio dos dados arqueológicos obtidos, é possível conseguir informações que o Espírito Santo irá usar para impressionar positivamente uma pessoa que está lutando contra a descrença (RANDALL, 2015). 
Diante de inúmeras descobertas da biologia evolutiva, arqueologia, cosmologia e outros ramos da ciência, divergências entre ciência e as descrições das Escrituras Sagradas estão reduzindo constantemente. Assim, diante desses novos estudos, este trabalho apresentou como objetivo realizar uma descrição das descobertas arqueológicas evidenciando a existência de pessoas, lugares e eventos descritos em solo bíblico descrito nas Escrituras Sagradas escrita a milhares de anos atrás.

\section{METODOLOGIA}

Trata-se de uma investigação de caráter observacional e descritivo das escrituras sagradas, artigos científicos e livros que retratam passagens descritas na Bíblia Sagrada que foram elucidadas por descobertas arqueológicas.

Para a composição da presente revisão foi realizado um levantamento bibliográfico de artigos científicos publicados até 2020 utilizando como descritores em português, isolados ou em combinação: Bíblia Sagrada; Arqueologia; Ciência; Humanidade; Confiabilidade. Na seleção do material, efetuaram-se três etapas. A primeira foi caracterizada pela pesquisa do material compreendida entre os meses de maio e julho de 2021 com a seleção de 27 trabalhos. A segunda compreendeu a leitura dos títulos e resumos dos trabalhos, visando uma maior aproximação e conhecimento, sendo excluídos os que não tivessem relação e relevância com o tema. Após essa seleção, buscaram-se os textos que se encontravam disponíveis na íntegra, totalizando 18 trabalhos, sendo estes, inclusos na revisão Figura 1 .

Figura 1. Fluxograma relativo às etapas de seleção dos artigos utilizados na pesquisa

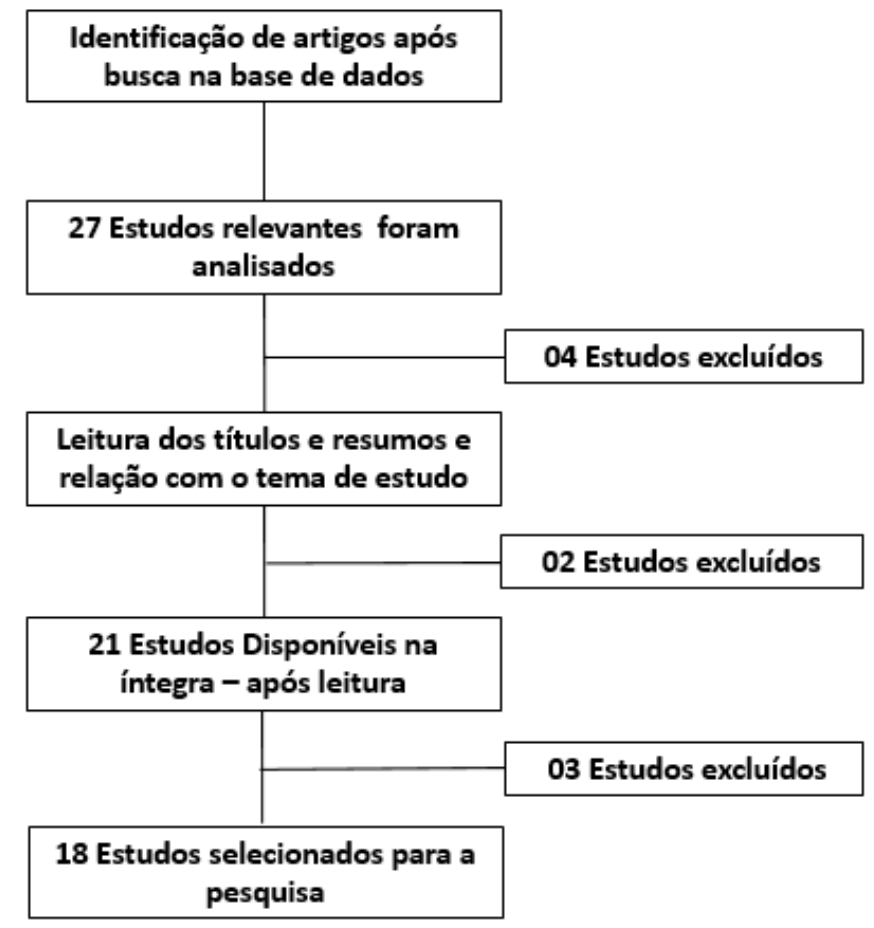


$\mathrm{Na}$ leitura e avaliação, os artigos que apresentaram os critérios de elegibilidade foram selecionados e incluídos na pesquisa por consenso. Como critério de exclusão utilizou-se referência incompleta e informações presentemente desacreditadas, uma vez que essa pesquisa pretendeu revisar conhecimentos atualizados sobre o tema.

\section{RESULTADOS E DISCUSSÃO}

O contexto deste trabalho visa conhecer exemplos de contribuições significativas da arqueologia visando uma melhor compreensão da história bíblica. De acordo com Randall (2015), desde quando se iniciaram as explorações modernas no antigo Oriente Próximo, a arqueologia tem verificado continuamente a existência de pessoas mencionadas na Bíblia, bem como, a ocorrência dos eventos descritos nas Escrituras Sagradas (RANDALL, 2015).

Esse mesmo autor relata em seu estudo que a primeira dessas descobertas foi feita em 1843, por Paul Emile Botta (1802-1870), que escavando em Khorsabad, conhecido como Dur Sharrukin (Castelo de Sargão), no Iraque encontrou uma série de tabletes cuneiformes, além de inscrições em baixo relevo. $\mathrm{Na}$ Europa, um estudioso por nome Longperrier conseguiu interpretar o nome Sar-gin em uma das inscrições, identificando esse nome com Sargão, rei da Assíria, mencionado em Isaías 20:1. Esse foi, de acordo com as informações desse estudioso, o primeiro personagem bíblico cuja existência foi confirmada de forma independente da Bíblia (RANDALL, 2015). Em Isaías 20:1 "No ano em que Tartã, enviado por Sargom, rei da Assíria, veio a Asdode, e guerreou contra ela, e a tomou" (BÍBLIA SAGRADA, 2011).

Em 1846, Edward Hincks, um clérigo irlandês, conseguiu decifrar o nome do rei Nabucodonosor II e de seu pai em tijolos de barro que os viajantes trouxeram de volta da Mesopotâmia. Isso confirmou a existência desse personagem que está registrado no livro de Daniel, bem como a sua reivindicação de ser o grande construtor da Babilônia (RANDALL, 2015). "No ano terceiro do reinado de Jeoiaquim, rei de Judá, veio Nabucodonosor, rei de babilônia, a Jerusalém, e a sitiou” Daniel 1:1 (BÍBLIA SAGRADA, 2011).

Uma equipe de arqueólogos escavando em 1961 um teatro construído por Herodes, o Grandes, em Cesareia, em Israel, foi descoberto uma pedra Figura 2 que possuía uma inscrição na lateral com os dizeres: "Pôncio Pilatos, prefeito da Judeia, a dedica", sendo este achado considerado uma importante evidência física da existência desse personagem bíblico (MARINA, 2017). A placa de $82 \mathrm{~cm}$ de largura e $68 \mathrm{~cm}$ de altura, que pode ser encontrada atualmente no Museu de Israel (Jerusalém), foi escrita em latim e colocada em uma das escadas do anfiteatro de Cesárea. A informação descrita coincide com o reinado do imperador Tibério entre os anos 14 e 37 d.C. e também com o cronograma bíblico descrito 
no Novo Testamento: Lucas, em seu Evangelho, se referiu a Pilatos como o governador romano da Judeia durante o reinado de Tibério César (MARINA, 2017). "E no ano quinze do império de Tibério César, sendo Pôncio Pilatos presidente da Judéia, e Herodes tetrarca da Galiléia, e seu irmão Filipe tetrarca da Ituréia e da província de Traconites, e Lisânias tetrarca de Abilene" Lucas 3:1 (BÍBLIA SAGRADA, 2011).

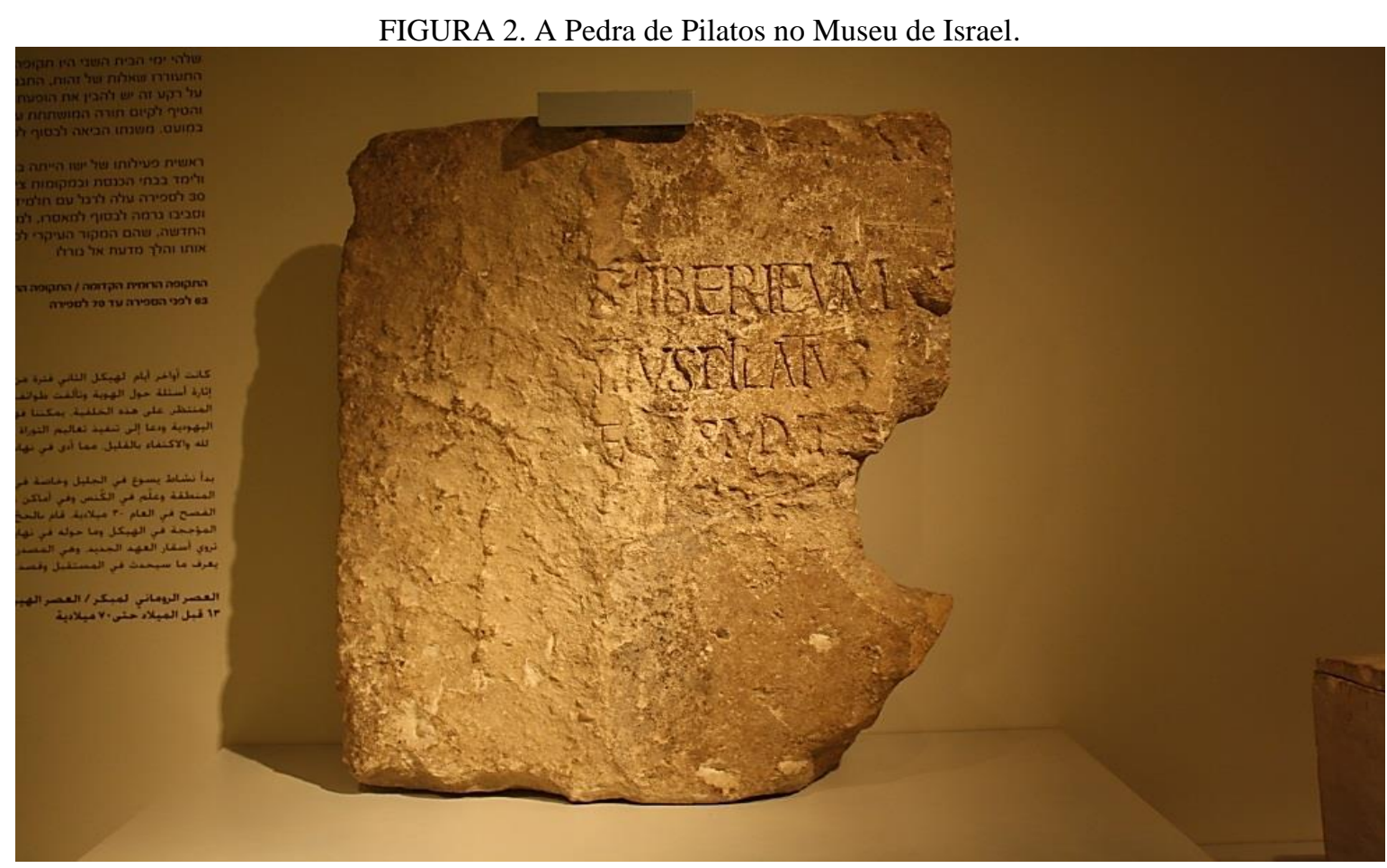

Extraído e modificado de Marina, 2017

No livro de João 9:4 está descrito "E disse-lhe: Vai, lava-te no tanque de Siloé (que significa o Enviado). Foi, pois, e lavou-se, e voltou enxergando (BÍBLIA SAGRADA, 2011). Nesta passagem após curar um cego de nascença, Jesus lava os olhos deste com as águas do Reservatório de Siloé. A comunidade acadêmica acreditava que João não estava fazendo uma referência a um determinado local, e sim, usando um conceito religioso para ilustrar a passagem, porém, em 2005, um grupo de profissionais encontrou a reserva de água na Cidade Velha de Jerusalém. Posteriormente, estudiosos notificados do achado tomaram parte da escavação e concluíram, no final dos estudos, que se tratava do Reservatório de Siloé (GALILEU, 2015). No livro de Isaias está descrito esse tanque "Porquanto este povo desprezou as águas de Siloé que correm brandamente, e alegrou-se com Rezim e com o filho de Remalias” Isaías 8:6 (BÍBLIA SAGRADA, 2011).

Outra passagem das Escrituras Sagradas elucidada está descrita no livro de 1 Reis 3:1 "E Salomão se aparentou com Faraó, rei do Egito; e tomou a filha de Faraó, e a trouxe à cidade de Davi, até que acabasse de edificar a sua casa, e a casa do SENHOR, e a muralha de Jerusalém em redor" 


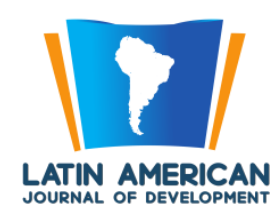

(BÍBLIA SAGRADA, 2011). Essa passagem inspirou a arqueóloga israelense Eilat Mazar, da Universidade Hebraica de Jerusalém, a buscar indícios do suposto muro. Foram três meses de escavações envolvendo 50 cientistas até que parte da provável muralha do rei Salomão fosse exposta. Segundo a pesquisadora, a muralha possuía 70 metros de comprimento e 6 metros de altura Figura 3, admitindo que a descoberta é a única capaz de aproximar a ciência moderna de uma construção provavelmente erguida durante o reinado salomônico (HEBREW UNIVERSITY OF JERUSALEM, 2010; CORREIO BRASILIENSE, 2010).

Figura 3. Seção de um muro da cidade antiga de Jerusalém, do século X a.C. - possivelmente construído pelo rei Salomão.

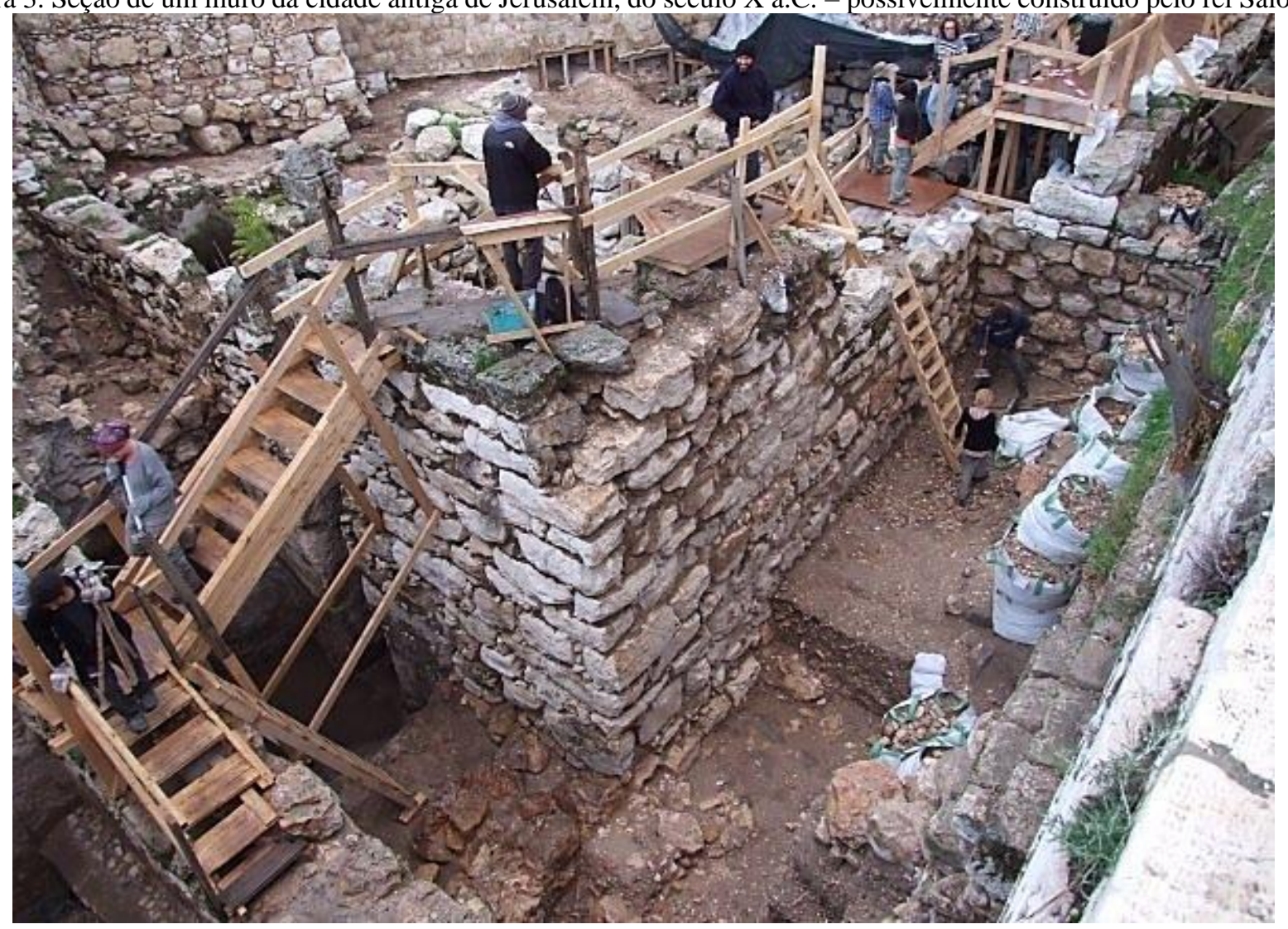

Extraído de Hebrew University of Jerusalem, 2010

Em 1968, outras descobertas foram feitas. Em Israel vários objetos, um deles possuia códigos que, na época, não foram decifrados. Trata-se de um anel de dois mil anos que ficou esquecido por um tempo até que, em novembro de 2018, um grupo de estudo da Universidade Hebraica decidiu analisálo usando novas tecnologias. Cientistas israelenses conseguiram decifrar essas inscrições e descobriram o nome de Pôncio Pilatos, que era o governador da província romana da Judeia na época em que os textos bíblicos afirmam que ele ordenou a crucificação de Jesus Cristo (FABAPAR, 2019). A ordenação da crucificação por Pôncio Pilatos "Então Pilatos julgou que devia fazer o que eles pediam. E soltou-lhes o que fora lançado na prisão por uma sedição e homicídio, que era o que pediam; mas 
entregou Jesus à vontade deles" Lucas 23:24-25 (BÍBLIA SAGRADA, 2011). Posteriormente, os arqueólogos conseguiram ler as inscrições usando sistemas de limpeza e com a ajuda de uma técnica especial de fotos do artefato arqueológico (FABAPAR, 2019). A inscrição do anel representa a imagem de uma taça de vinho com uma palavra em grego traduzida como "Pilatos", que foi imediatamente ligada ao governador romano Figura 4.

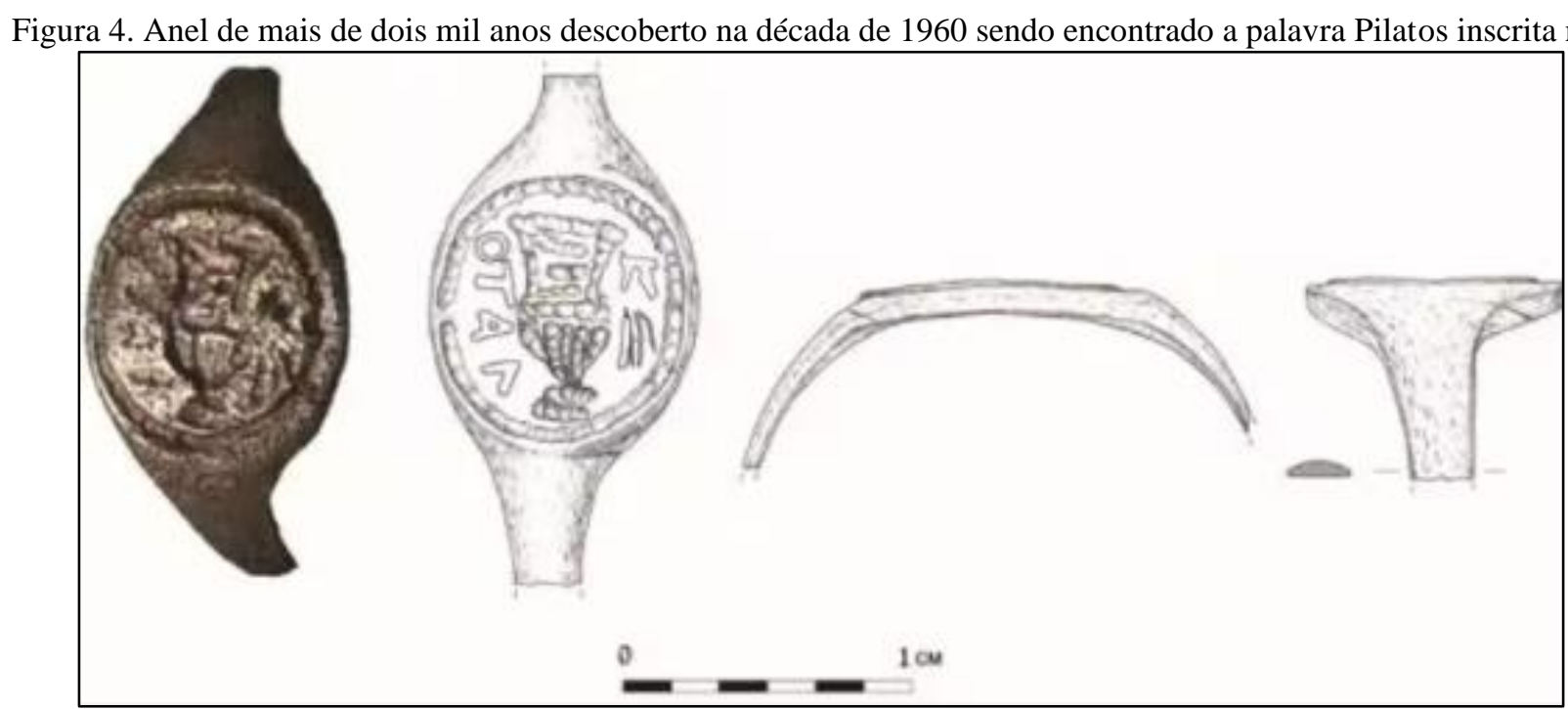

Extraído e modificado de Encontro, 2018

Como os objetivos deste artigo não foi retratar todas as descobertas arqueológicas já descritas na literatura especializada, finalizamos esse compendio de relatos que representou a maior conquista da arqueologia do século 20 - os Fragmentos de pergaminho bíblico achados em caverna no deserto da Judeia conhecidos como Manuscritos do Mar Morto.

Em 1947, dois beduínos árabes, percorrendo a região montanhosa e árida de Hirbet Qumran, no deserto da Judeia, a 12 quilômetros ao sul de Jericó, em Israel Figura 5A, entraram numa das várias cavernas do lugar e ali se depararam com vasos longos e cilíndricos Figura 5B, que continham manuscritos muito antigos, alguns em estado fragmentário. Um desses documentos identificado mais tarde era uma cópia do livro bíblico de Isaías produzida entre 125 e 100 antes de Cristo Figura 5C (CASTRO, 2017).

Atraídos pela descoberta inicial, pesquisadores vasculharam a área localizada na região noroeste do Mar Morto, e ao longo de nove anos, entre 1947 e 1956 (CASTRO, 2017). Os manuscritos que foram encontrados nas onze grutas são escritos, em couro ou papiros, em sua maioria na língua hebraica e alguns poucos em aramaico ou grego. Alguns estavam em bom estado e outros estavam bastante deteriorados com o tempo e as condições em que foram guardados. Ao todo foram encontrados em torno de 800 documentos (PERONDI, 2011). 
Esses textos são cópias fiéis, que os habitantes da região de Qumran transcreveram dos livros do Antigo Testamento, cerca de 225 manuscritos. O Livro dos Salmos é o que foi encontrado em maior número de cópias; o segundo foi Deuteronômio; e o terceiro Isaías, os quais curiosamente são também esses os livros mais citados pelo Novo Testamento. Somente dos livros de Ester e Neemias não foi encontrada nenhuma cópia (PERONDI, 2011). Não foram encontrados textos do Novo Testamento, mas o conhecimento da comunidade que vivia em Qumran veio confirmar muitos dados contidos no Novo Testamento Figura 5D.

Figura 5. Em A, Qumran, a noroeste do Mar Morto: em 11 cavernas da região onde foram encontrados os manuscritos antigos; B, Réplica dos vasos onde estavam guardados os manuscritos; C, Fragmentos de um dos pergaminhos do livro de Isaías; D, Escavações nas cavernas de Qumran trouxeram à luz fragmentos materiais que reconstituem aspectos da vida da comunidade que produziu os Manuscritos do Mar Morto.
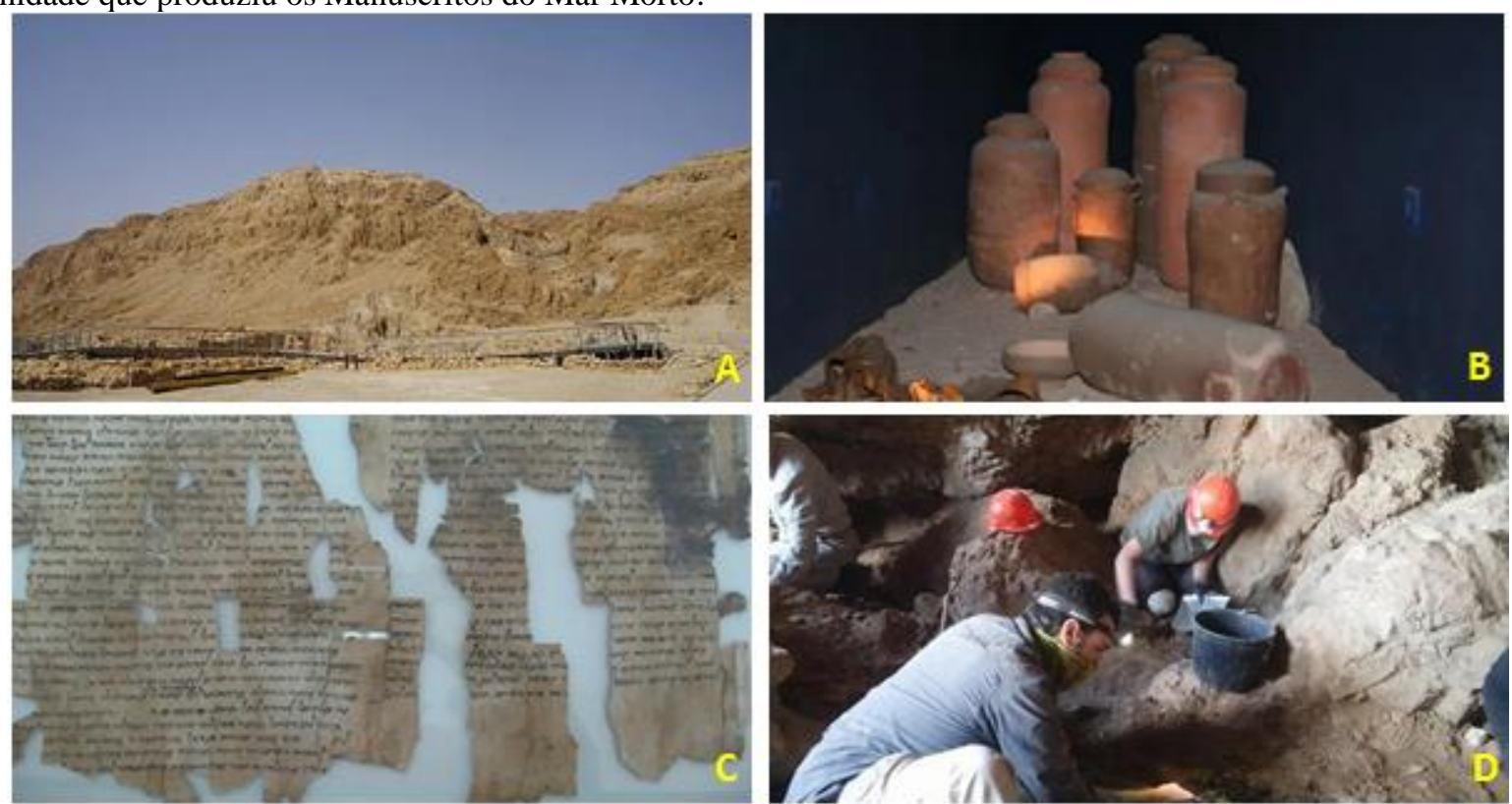

Extraído e modificado de Castro, 2017

Atualmente, os manuscritos encontrados em Qumran estão guardados no Santuário do Livro, uma ala do Museu de Israel, em Jerusalém. Boa parte deles foi publicada entre 1955 e 2009 pela Oxford University Press, na série Discoveries in the Judean Desert (CASTRO, 2017).

\section{CONSIDERAÇÕES FINAIS}

Comparado com documentos produzidos há milhares de anos, assim como, os da atualidade é possível afirmar que as Escrituras Sagradas são as melhores preservadas, servindo de estímulos e instigando inúmeros estudos nos mais variados ramos da ciência contemporânea. Desde a época das escavações sistemáticas realizadas por Heinrich Schliemann, considerado o pai da Arqueologia, em Tróia no século passado, se passaram muitos anos até iniciar a pesquisa do solo descrito pela Bíblia Sagrada. Neste estudo, foi realizado um relato das descobertas arqueológicas diante das Escrituras 
Sagradas dentro de um contexto que aceita a Bíblia como sendo totalmente inspirada e autorizada na Palavra de Deus, devendo essas descobertas serem utilizadas de forma proveitosa para esclarecer e corroborar com as declarações desse livro sagrado e devendo ser usadas para a edificação de toda a humanidade "Toda a Escritura é inspirada por Deus e útil para o ensino, para a repreensão, para a correção e para a instrução na justiça" 2 Timóteo 3:16.

No entanto, esta coletânea de livros e documentos ainda é questionada por cientistas, historiadores e demais pesquisadores. Porém, afirmações desse Livro Sagrado são continuamente confirmadas através de novas escavações e achados arqueológicos com a utilização das tecnologias atuais, o que vem favorecendo uma redução de possíveis divergências. Reforçamos que o objetivo dos autores não foi retratar todas as descobertas arqueológicas em relação as Escrituras Sagradas, mas pontos importantes desse livro sagrado concluindo não existir um motivo para que todos os outros não sejam verdadeiros. Assim, através da História, podemos encontrar Deus atuando, e porque Ele está no comando da História, ela pode ser entendida da melhor forma quando o pesquisador mantém um relacionamento com Ele.

Por fim, devemos levar em consideração a declaração dos próprios escritores desse Livro Sagrado "Sabendo primeiramente isto: que nenhuma profecia da Escritura é de particular interpretação. Porque a profecia nunca foi produzida por vontade de homem algum, mas os homens santos de Deus falaram inspirados pelo Espírito Santo" 2 Pedro 1:19,20. 


\section{REFERENCIAS. BIBLIOGRÁFICAS}

ALMEIDA, J. F. BÍBLIA SAGRADA contendo o Antigo e o Novo Testamento, $1^{\text {a }}$ ed. Ed. Geográfica, 2011.

CRAMPTON, W. G. A Visão Bíblica da Ciência. Monergismo, 2018.

LAPA, M. A. T. Caderno de estudos: introdução à sagrada escritura e bibliologia. Centro Universitário Leonardo da Vinci. UNIASSELVI, 2009.

MARCUM, J. A. Explorando as Fronteiras Racionais entre as Ciências Naturais e a Teologia Cristã. Revista de Estudos da Religião março / 2007 / pp. 34-58.

MARTELLI, A. Evolução sobre a trajetória de um homem com Neoplasia de reto retratando o princípio do Evangelho e que se faz presente nos dias atuais. DOXIA, Serra, v.4, n.6, p. 3-11, Jan-Jun. 2019.

MARTELLI, A.; MARTELLI, F. P. Fenômenos e acontecimentos descritos nas escrituras sagradas são endossados pela ciência contemporânea. Braz. J. Technol., Curitiba, v. 3, n. 3, p. 90-102, jul./set. 2020.

MAZZAROLO, I.; FERNANDES, L. A.; LIMA, M. L. C. Exegese, Teologia e Pastoral: relações, tensões e desafios. Santo André: Academia Cristã; Rio de Janeiro: PUC-Rio, p. 395-418, 2015.

RICAS, C. V. Fé \& Ciência O Conhecimento Científico à Luz Das Sagradas Escrituras, v. 02, 2013.

KAEFER, J. A. A Bíblia, a arqueologia e a história e a história de Israel e Judá. São Paulo: Paulus, 2015.

RANDALL W. Y. Até que ponto as descobertas arqueológicas confirmam a Bíblia? Diálogo. v. 27, n. $2,2015$.

Marina, D. L. Pôncio Pilatos existiu de verdade? Evidência arqueológica demonstra. ACI DIGITAL. Disponível em: <https://www.acidigital.com/noticias/poncio-pilatos-existiu-de-verdade-evidenciaarqueologica-demonstra-89451> Acesso, jul, 2021.

CORREIO BRASILIENSE, Arqueóloga israelense descobre muralha de $6 \mathrm{~m}$ de altura e $70 \mathrm{~m}$ de comprimento construída há 3 mil anos, 2010. Disponível Em: <https://www.correiobraziliense.com.br/app/noticia/ciencia-e-

saude/2010/02/26/interna_ciencia_saude,176013/arqueologa-israelense-descobre-muralha-de-6m-dealtura-e-70m-de-comprimento-construida-ha-3-mil-anos.shtml> Acesso, jul, 2021.

REVISTA GALILEU. Evidências científicas que dão sentido a episódios da Bíblia. Disponível em: $<$ https://revistagalileu.globo.com/Sociedade/noticia/2015/07/5-evidencias-cientificas-que-daosentido-episodios-da-biblia.html $>$ Acesso, jun, 2021.

REVISTA ENCONTRO. Anel descoberto na década de 1960 seria de Pôncio Pilatos Disponível em: <https://www.revistaencontro.com.br/canal/internacional/2018/11/anel-descoberto-na-decada-de1960-seria-de-poncio-pilatos.html> Acesso, jun, 2021.

FABAPAR. Descobertas arqueológicas relacionadas à Bíblia, 2019. Disponível em: <https://fabapar.com.br/blog/descobertas-arqueologicas-relacionadas-a-biblia/> Acesso, jun, 2021. 
PERONDI, I. Os Manuscritos de Qumran ou do Mar Morto. Rev. Pistis Prax. Teol. Pastor., Curitiba, v. 3, n. 1, p. 205-219, jan./jun. 2011.

CASTRO, R. C. G. Manuscritos do Mar Morto ainda guardam mistérios, 70 anos depois Jornal da USP, 2017. Disponível em: <https://jornal.usp.br/cultura/manuscritos-do-mar-morto-ainda-guardammisterios-70-anos-depois/> Acesso em jul, 2021..

HEBREW UNIVERSITY OF JERUSALEM. Arqueólogo da Universidade Hebraica descobre a muralha da cidade de Jerusalém do século X a.C. Disponível em: <http://www.huji.ac.il/cgibin/dovrut/dovrut_search_eng.pl?mesge126691593732688760> Acesso,jun, 2021. 